\title{
Clinical practice competency and associated factors among graduating nursing students attending at Universities in Amhara region, Ethiopia: Institution based cross-sectional study, 2018
}

Addisu Getie ( $\square$ addisugetie@gmail.com )

Woldia University

Yosief Tsige

Addis Ababa University College of Health Sciences

Emebet Birhanie

Addis Ababa University College of Health Sciences

Kenean Getaneh

Woldia University

Asmamaw Demis

Woldia University

\section{Research note}

Keywords: Competency, Clinical practice, Graduating Nursing students, Universities

Posted Date: October 17th, 2019

DOI: https://doi.org/10.21203/rs.2.10757/v2

License: (c) (1) This work is licensed under a Creative Commons Attribution 4.0 International License.

Read Full License 


\section{Abstract}

Objective To assess clinical practice competency and associated factors among graduating nursing students in universities of Amhara region, Northern Ethiopia. Result This study showed that, $33.6 \%$ of the participants were clinically competent and there is slight variation in the clinical competency of participants at different Universities found in Amhara region. Clinical practice competency of students was affected by clinical instructor factors. Students who had got orientation about objective of clinical practice were 2.387 times more likely to be clinically competent [AOR: $2.387 ; 95 \% \mathrm{Cl}(1.011-5.635)$ ]. Students who had clinical instructor who spent enough time for mentoring them during clinical practice had 2.247 times more likely to be clinical competent [AOR: 2.247; 95\% Cl (1.100-4.593)]. Students who had instructors that follow them while they conduct a procedure were 2.655 times more likely clinically competent [AOR: $2.655 ; 95 \% \mathrm{Cl}(1.294-5.449)]$. This study also revealed that clinical practice competency of students was affected by assessment methods factors. Students with clinical practice assessment checklist had 2.663 times higher clinical practice competency [AOR: 2.663; 95\% Cl (1.324-5.358)]. Regarding staff-student factors, students who were allowed to perform tasks by clinical staffs were 5.858 times more likely to be clinical competent task [AOR: 5.858; 95\% $\mathrm{Cl}(2.657-12.916)]$

\section{Introduction}

Nursing is a dynamic, caring, and helping relationship in which nurses assist the client to achieve and obtain optimal health. As a profession, it undergoes a huge transformation since the time of Florence nightingale (1). Graduating nurse should apply the core competencies which are professional role, responsibility and accountability; health assessment and diagnosis; therapeutic management; and health promotion and prevention of illness and injury $(2,3)$.

Clinical practice is the means by which nursing students learn to apply theory of nursing, facilitating integration of theoretical knowledge and practical skills in the clinical setting (4-6). One of the outcomes for effective learning in clinical practice is clinical competence which is the ability to successfully apply professional knowledge, skill and attitude to new situations as well as familiar ones $(1,7)$.

Health workers, including nurses, are not adequately prepared to meet the needs of society, especially in developing countries. The rapidly shifting of balance in availability and demands of competent health care workforce and the change in health care system have highlighted the necessity for graduating students to be clinical competent (10). A global report into health education sees educational institutions as crucial to transform health care systems. However, in many countries there is a lack of capacity in training, budget support and infrastructure (1). Improving the productivity and performance of health care workers in order to enhance efficiency in health interventions, is a major challenge for African countries (13).

In Ethiopia, government is the main health care service provider. The health care system of Ethiopia is facing a serious shortage of skillful health workforce. So, when students start clinical practice, they 
encounter different problems that can affect their clinical competency (14). Therefore, the purpose of this study was to assess clinical competency and associated factors among graduating nursing students at Universities found in Amara Region, Northern Ethiopia, 2018.

\section{Methods}

\section{Study design and setting}

Institutional based cross-sectional study design was conducted from February 25 -April 25/2018 G.C among graduating nursing students at universities found in Amhara region namely University of Gondar, Bahir Dar University, Wollo University, Debre Birhan University, Debre Markos University and Woldia University.

\section{Source and study Population}

The source populations were all graduating BSc nursing students attending in Amara Region Universities whereas the study populations were all randomly selected graduating BSc nursing students in Amara Region Universities in 2018.

\section{Inclusion and Exclusion Criteria}

Graduating BSc nursing students attending regular degree program were included, whereas students who were critically ill during data collection period were excluded.

\section{Sample Size Determination}

Sample size was calculated using a single population proportion formula with the assumptions of $\mathrm{P}$ value $=0.25$ which was the proportion of clinical practice competency in Hawasa university (4), a 95\% confidence level, $5 \%$ margin of error and $10 \%$ non-response rate. Accordingly, the calculated final sample size of the study was found to be 307 .

\section{Sampling and Sampling Procedure}

All universities having graduating nursing students were included in the study, and total sample size was proportionally allocated to each university. The lists of graduating students were obtained from the respective university registrar. Then, the study participants from each university were selected by computer generated simple random sampling technique.

\section{Data Collection Method}

The data was collected by six BSc nurses' by using a pretested structured self-administered questionnaire and observational checklist which was adapted from previous studies which was conducted in Hawassa Ethiopia and international domains of competency for nurses $(4,6,34)$. Since, English language is the medium of instruction in all Ethiopian nursing schools, it was used for the questionnaire and 
observational checklist. Factors associated with clinical practice competency was assessed by 29 reliable items (Cronbach's alpha $=0.78$ ) (items on clinical instructor factor, clinical environment, assessment method and clinical staff student interaction factors). The non-participatory observation was done prior to distributing self-administered questionnaire and oral consent was given for those nurse students who was observed but not the detail of observation. Observation was undertaken on $10 \%$ of the study population by using observational checklist to assess the actual clinical practice competency among graduating nurses which was used as a supplement study for the quantitative results.

\section{Data Quality Assurance}

Training was given for data collectors and supervisors about techniques of data collection and briefed on each question included in the data collection tool. The pre-test was conducted on $5 \%$ of sample size to ensure the validity of the tool, then correction was made before the actual data collection. Principal investigator and supervisors were checked on the spot and reviewed all the questionnaires to ensure completeness and consistency of the information collected and immediate action was taken accordingly. Double data entry was done by two data clerks and consistency of the entered data was cross-checked by comparing the two separately entered data.

\section{Data processing and Analysis}

The data were entered using Epi Data version 4.2 and exported to SPSS version 24 for analysis. Descriptive statistics like frequency, percentage and standard deviation was computed. Binary logistics regression model was applied to identify factors associated with clinical practice competency. For analysis of clinical practice competency, all questions were coded as yes and no response and finally those graduating students who score $50 \%$ and above were labeled as clinically competent and those who scored below $50 \%$ were labeled as clinically incompetent. Observational data was analyzed using and the result was carefully triangulated to validate the quantitative result. All variables with $P \leq 0.25$ in the bivariate analysis were included in the final model of multivariate analysis in order to control all possible confounders. Multi-collinearity was checked to see the linear correlation among the independent variables by using standard error. Variables with a standard error of $>2$ were dropped from the multivariable analysis. Model fitness was checked with the Hosmer-Lemeshow test. Adjusted odds ratio with $95 \% \mathrm{Cl}$ was estimated to identify the factors associated with clinical practice competency using multivariable logistic regression analysis. Level of statistical significance was declared at $p$-value $<0.05$.

\section{Result}

\section{Socio-Demographic Characteristics}

A total of 307 graduating nursing students were participated. One hundred seventy three students were males. Regarding to age, $(82.4 \%)$ of students were in the range between $20-24$ years and the mean ( \pm SD) age was $22.68( \pm 1.841)$ years. One hundred sixty one $(52.4 \%)$ of the students were followers of orthodox Christianity (Table 1 S1). 
Overall self-reported Clinical Practice Competency Level

This study revealed that, $103(33.6 \%)$ of the participants was clinically competent and there is slight variation in clinical competency of participants at Universities found in Amhara region, Northern Ethiopia (Figure 1).

\section{Clinical competency level from Observational Checklist}

Observations were made on $31(10 \%)$ of graduating nursing students during their practical session in medical, surgical, obstetrics and gynecology, pediatrics and outpatient department to validate selfreported practice. To determine the practice and validate their responses, 13 observation checklists were analyzed. Out of 31 observed participants, $5(16.1 \%)$ of them had instructors that demonstrate skills in cases during clinical practice and, only $7(22.6 \%)$ of students got constructive feedback from their clinical instructors (Table 1).

Table 1: Clinical competency practice result among graduating nursing students at universities in Amhara region, Northern Ethiopia, 2018.

\begin{tabular}{|c|c|c|c|c|}
\hline \multirow[t]{2}{*}{ Observational items } & \multicolumn{2}{|l|}{ Yes } & \multicolumn{2}{|l|}{ No } \\
\hline & Frequency & $\%$ & Frequency & $\%$ \\
\hline Instructors provide clinical practice logbook & 12 & 38.7 & 19 & 61.3 \\
\hline Instructors have continuous follow up & 14 & 43.2 & 17 & 54.8 \\
\hline Instructor integrate theory in to practice & 16 & 51.6 & 15 & 48.4 \\
\hline Instructors demonstrate skills in cases & 5 & 16.1 & 26 & 83.9 \\
\hline Instructors provide constructive feedback & 7 & 22.6 & 24 & 77.4 \\
\hline Place of attachment has sufficient cases & 10 & 32.3 & 21 & 67.7 \\
\hline Clinical environment has sufficient materials & 8 & 25.8 & 23 & 74.2 \\
\hline Clinical placement has sufficient wards for & 9 & 29.0 & 22 & 71.0 \\
\hline Orientation about assessment methods & 9 & 29.0 & 22 & 71.0 \\
\hline Presence of continuous assessment methods & 8 & 25.8 & 23 & 74.2 \\
\hline Assessment address three learning domain & 8 & 25.8 & 23 & 74.2 \\
\hline Staff allows students to perform tasks & 9 & 29.0 & 22 & 71.0 \\
\hline Staff encourages students & 8 & 25.8 & 23 & 74.2 \\
\hline \multirow[t]{2}{*}{ Over all observed clinical competency } & \multicolumn{4}{|c|}{ Clinically competent: $9(29 \%)$} \\
\hline & \multicolumn{4}{|c|}{ Clinically incompetent: $22(71 \%)$} \\
\hline
\end{tabular}

Factors Associated with Clinical Practice Competency 
Logistic regression analysis revealed that, students who had got orientation about objective of clinical practice were 2.39 times more likely to be clinically competent compared to the counterpart [AOR: 2.39; $95 \% \mathrm{Cl}: 1.01-5.63]$. Similarly, students who had clinical instructor who spent enough time for mentoring them during clinical practice had 2.25 times more likely to be clinical competent [AOR: $2.25 ; 95 \% \mathrm{Cl}$ : 1.104.59]. Students who had instructors follow them while conducts a procedure were 2.66 times more clinically competent than who were not followed by instructors [AOR: $2.66 ; 95 \% \mathrm{Cl}: 1.29-5.45]$. This study also revealed that, clinical practice competency of students was affected by assessment methods factors. Students with clinical practice assessment checklist had 2.66 times higher clinical practice competency than student who had no clinical assessment checklist [AOR: 2.66; 95\% Cl: 1.32-5.36]. Regarding clinical staff-student factors, students who were allowed to perform tasks by clinical staffs were 5.86 times more likely to be clinical competent than those who were not allowed [AOR: 5.86; $95 \% \mathrm{Cl}$ : 2.66-12.92] (Table 2).

Table 2: factors associated with clinical practice competency among graduating nursing students at universities in Amhara region, Northern Ethiopia, 2018 ( $n=307)$. 


\begin{tabular}{|c|c|c|c|c|c|}
\hline \multicolumn{2}{|l|}{ Variables } & $\begin{array}{l}\text { Clinical } \\
\text { competency }\end{array}$ & practice & COR(95\%CI) & AOR(95\%CI) \\
\hline \multirow[t]{2}{*}{ Orientation of objective } & Yes & $\begin{array}{l}\text { Competent } \\
80(47.9 \%)\end{array}$ & $\begin{array}{l}\text { Incompetent } \\
87(52.1 \%)\end{array}$ & $\begin{array}{l}4.68(2.72- \\
8.03) * * *\end{array}$ & $\begin{array}{l}2.39(1.01- \\
5.63) *\end{array}$ \\
\hline & No & $23(16.43 \%)$ & $117(83.57 \%)$ & 1.00 & 1.00 \\
\hline \multirow[t]{2}{*}{ Enough mentoring time } & Yes & $62(50.8 \%)$ & $60(49.2 \%)$ & $\begin{array}{l}3.63(2.21- \\
5.96) * * *\end{array}$ & $\begin{array}{l}2.25(1.10- \\
4.59) *\end{array}$ \\
\hline & No & $41(22.2 \%)$ & $144(77.8 \%)$ & 1.00 & 1.00 \\
\hline \multirow[t]{2}{*}{$\begin{array}{l}\text { Integrate theory in to } \\
\text { practice }\end{array}$} & Yes & $77(39.9 \%)$ & $116(60.1 \%)$ & $\begin{array}{l}2.25(1.33- \\
3.79)^{* *}\end{array}$ & $\begin{array}{l}1.01(0.49- \\
2.07)\end{array}$ \\
\hline & No & $26(22.8 \%)$ & $88(77.2 \%)$ & 1.00 & 1.00 \\
\hline \multirow{2}{*}{$\begin{array}{l}\text { Demonstrate skills in } \\
\text { cases }\end{array}$} & Yes & $66(47.8 \%)$ & $72(52.2 \%)$ & $\begin{array}{l}3.27(1.99- \\
5.36)^{* * *}\end{array}$ & $\begin{array}{l}1.559(0.72- \\
3.36)\end{array}$ \\
\hline & No & $37(21.9 \%)$ & $132(78.1 \%)$ & 1.00 & 1.00 \\
\hline \multirow[t]{2}{*}{$\begin{array}{l}\text { Follow while doing } \\
\text { procedure }\end{array}$} & Yes & $56(54.4 \%)$ & $47(45.6 \%)$ & $\begin{array}{l}3.98(2.39- \\
6.60) * * *\end{array}$ & $\begin{array}{l}2.66(1.29- \\
5.45) * *\end{array}$ \\
\hline & No & $47(23.0 \%)$ & $157(77.0 \%)$ & 1.00 & 1.00 \\
\hline \multirow[t]{2}{*}{$\begin{array}{l}\text { Orient assessment } \\
\text { methods }\end{array}$} & Yes & $72(42.9 \%)$ & $96(57.1 \%)$ & $\begin{array}{l}2.61(1.58- \\
4.32)^{* * *}\end{array}$ & $\begin{array}{l}0.76(0.35- \\
1.65)\end{array}$ \\
\hline & No & $31(22.3 \%)$ & $108(77.7 \%)$ & 1.00 & 1.00 \\
\hline \multirow[t]{2}{*}{ Continuous assessment } & Yes & $70(42.2 \%)$ & $96(57.8 \%)$ & $\begin{array}{l}2.39(1.45- \\
3.92)^{* *}\end{array}$ & $\begin{array}{l}1.26(0.60- \\
2.61)\end{array}$ \\
\hline & No & $33(23.4 \%)$ & $108(76.6 \%)$ & 1.00 & 1.00 \\
\hline \multirow[t]{2}{*}{ Presence of checklist } & Yes & 67(52.76\%) & $60(47.24 \%)$ & $\begin{array}{l}4.47(2.69- \\
7.40) * * *\end{array}$ & $\begin{array}{l}2.66(1.32- \\
5.36)^{* *}\end{array}$ \\
\hline & No & $36(20.0 \%)$ & $144(80.0 \%)$ & 1.00 & 1.00 \\
\hline \multirow[t]{2}{*}{$\begin{array}{l}\text { Staff allows to perform } \\
\text { tasks }\end{array}$} & Yes & 89(46.84\%) & 101(53.16\%) & $\begin{array}{l}\text { 6.48(3.46- } \\
12.13)^{* * *}\end{array}$ & $\begin{array}{l}5.86(2.66- \\
12.92) * * *\end{array}$ \\
\hline & No & $14(12.0 \%)$ & $103(88.0 \%)$ & 1.00 & 1.00 \\
\hline \multirow[t]{2}{*}{$\begin{array}{l}\text { Staff encourages to do } \\
\text { practice }\end{array}$} & Yes & $82(42.27 \%)$ & $112(57.73 \%)$ & $\begin{array}{l}3.21(1.84- \\
5.58) * * *\end{array}$ & $\begin{array}{l}1.30(0.57- \\
2.95)\end{array}$ \\
\hline & No & $21(18.58 \%)$ & $92(81.42 \%)$ & 1.00 & 1.00 \\
\hline
\end{tabular}

Significant at: $* \mathrm{P}<0.05, * * \mathrm{P}<0.01, * * * \mathrm{P}<0.001,1.00=$ reference, $\mathrm{COR}=$ Crude Odd Ratio, AOR=Adjusted Odd Ratio, CI=confidence Interval. 


\section{Discussion}

This study revealed that clinical practice competency of students was $33.6 \%$ with (95\% $\mathrm{Cl} 27.6 \%-39.6 \%$ ). This study was also supported with observational report in which only $29 \%$ of study participants were clinically competent. It is higher than a study done in Hawasa University which was $25.2 \%$. This discrepancy might be due to the difference of study setting and characteristics of study participants as well as technique of data collection. The study conducted in Hawasa was in a single institution, but this study covered six institutions (4). It is lower than study conducted in Health Professionals at Debre Birhan Health Science College which was $78.6 \%$. This may be due to the fact that, the study participants were health professionals (18). The result of this study is also inconsistent with a study conducted in Annals' University of Finland which was $66.7 \%$ (9). This might be due to the difference in sample size in which, the previous study use small sample size compared to this study, socio- economic status of study participant and difference in curriculum of the nation.

This study found that, those students who had got orientation about objective of clinical practice were 2.39 times more likely to be clinically competent than student who did not get orientation. Students who spend adequate time with their instructor/mentor during clinical practice were 2.25 times more competent in clinical skill than those who did not get chance to spend enough time with their clinical instructors. Students who had instructors who supervise them while they conduct a procedure were 2.66 times more competent in clinical performance than students who were not followed by instructors during conducting a procedure. This study also revealed that, those students who were assessed in clinical practice with assessment checklist had 2.66 times higher clinical practice competency than student who were not assessed with assessment checklist during their clinical practice. However, this result is inconsistent with the study conducted at Hawasa University among health science students which showed no significant association between those factors. This difference might be due to the difference in the characteristics of study participants and technique of data collection. In this study observation technique was used in addition to self-administered questionnaire(4). This finding is enlargement with the study conducted at Hawasa University. It also enlargement with a study conducted at Oman (24). This variation might be due to the difference in sampling technique, sample size, study setting and socio-economic status of study participants in which the previous study's sample size was relatively smaller than the current study and also it was used non-probability sampling technique, but this study used probability sampling method. In the current study clinical instructor factor had effect on clinical practice competency which is similar with the study conducted in Annals' University of Finland among graduating nursing students department of Nursing Science (9).

\section{Conclusions}

Generally, the results of this study revealed that about more than half of graduating nursing students were clinically incompetent. Clinical instructor variables like presence of orientation about the objective of clinical practice, spending enough time for mentoring and following of students while they conduct a procedure; assessment method factors like presence of assessment checklist; and staff-student 
interaction factors like allowing them to do a task were significantly associated with clinical practice competency of graduating nursing students. So, school administrators and respective responsible bodies should strengthen supportive supervision and updated orientation of students before and during their clinical attachments to improve clinical competency level of graduating nursing students.

\section{Limitations of the Study}

This study might suffer from recall bias and social desirability bias. There might be also a possibility of Howthorneffect on observational study.

\section{List Of Abbreviations}

AAU: Addis Ababa University; ANS: American Nursing Association; COC: Certificate of Competency; DEUM: Dedicated Education Unit Model; HWs: Health Workers; PI: Principal Investigator; RN: Registered Nurse; SPSS: Statistical Package for Social Sciences, WHO: World Health Organization

\section{Declarations}

\section{Acknowledgement}

The researchers would like to thank Addis Ababa University, College of health Science for permitting to conduct this research. We would like to thank our data collectors and study subjects who were volunteered and took their time to give us all the relevant information for the study.

\section{Author's Contributions}

AG conceived the study, wrote the study proposal, conducted the field work, supervised data entry, analyzed the data and wrote the manuscript. YT participated in refining the research proposal, supervised the field activity, analyzed the data and wrote the manuscript. EB, KG and AD participated in refining the research proposal, supervised the field activity and analyzed the data. All authors participated and approved the final manuscript.

\section{Funding}

The funding organization is Addis Ababa University. There is no role in the development of the paper except logistic one.

\section{Availability of data and material}

The datasets used for analysis during the current study are available from the corresponding author on reasonable request.

\section{Ethical approval and consent form}


Paper of approval and letter for permission was obtained before the beginning of data collection from departmental review board of Nursing and Midwifery, College of Health Science, Addis Ababa University. Permission letter was provided for Amara region Universities. Written informed consent was provided for study participant and they were explained clearly about the purpose and procedure of data collection, and their confidentiality were ensured.

\section{Consent for publication}

Not applicable

\section{Competing interest}

The authors declare that, they have no competing interest

\section{Author details}

${ }^{1}$ Department of Nursing, College of Health Sciences, Woldia University, Woldia, Ethiopia.

${ }^{2}$ School of Nursing and Midwifery, College of Health Sciences, Addis Ababa University, Addis Ababa, Ethiopia.

\section{References}

1. Wong BSH. Clinical Competency: experience of new graduated nurses from bachelor degree of nursing in University Malaysia Sarawak. 2013.

2. Al-Neami I, Dimabayao, Cynthia G. ${ }^{2}$., Caculitan, Elizer R. ${ }^{3}$. Competencies of Nursing Interns at King Fahd Central Hospital. IOSR Journal of Nursing and Health Science (IOSR-JNHS). 2014;3(2):34-44.

3. Association CN. Canadian nurse practitioner core competency framework. Ottawa, ON: Author. 2010.

4. Fikre R. Assessment of Factors Affecting Clinical Practice Competency of Undergraduate Health Science Students in Hawassa University, South, Ethiopia. Annals of Clinical and Laboratory Research. 2016.

5. E Potgieter D. Student nurses' experiences during clinical practice in the Limpopo Province. 2008.

6. (ABA) ABA. DOMAIN OF COMPETENCY.Competence assessment tool for nurses. 2015.

7. Kylmänen $P$, Spasic A. Assessing competence in technical skills of theatre nurses in India and Sweden: Evaluation of an observational tool. 2010.

8. Policy plus evidence iaoih. Nursing competence: what are we assessing and how should it be measured? 2009(18).

9. Kajander-Unkuri S. Nurse competence of graduating nursing students. 2015.

10. Kilminster S CD, Grant J, Jolly B. AMEE Guide No. 27: effective educational and clinical supervision. Med Teach. 2007;29(1):2-19.

11. Organization WH. Nurse educator core competencies. 2016. 
12. Nehrir B, Vanaki Z, Mokhtari Nouri J, Khademolhosseini SM, Ebadi A. Competency in Nursing Students: A Systematic Review. International Journal of Travel Medicine and Global Health. 2016;4(1):3-11.

13. Fitzgerald M, Gibson F, Gunn K. Contemporary issues relating to assessment of pre-registration nursing students in practice. Nurse education in practice. 2010;10(3):158-63.

14. Higher Education Relevance and Quality Agency: Quality of Education: Report MoE, Addis Ababa; 2008-2010; pp 5-10.

\section{Figures}

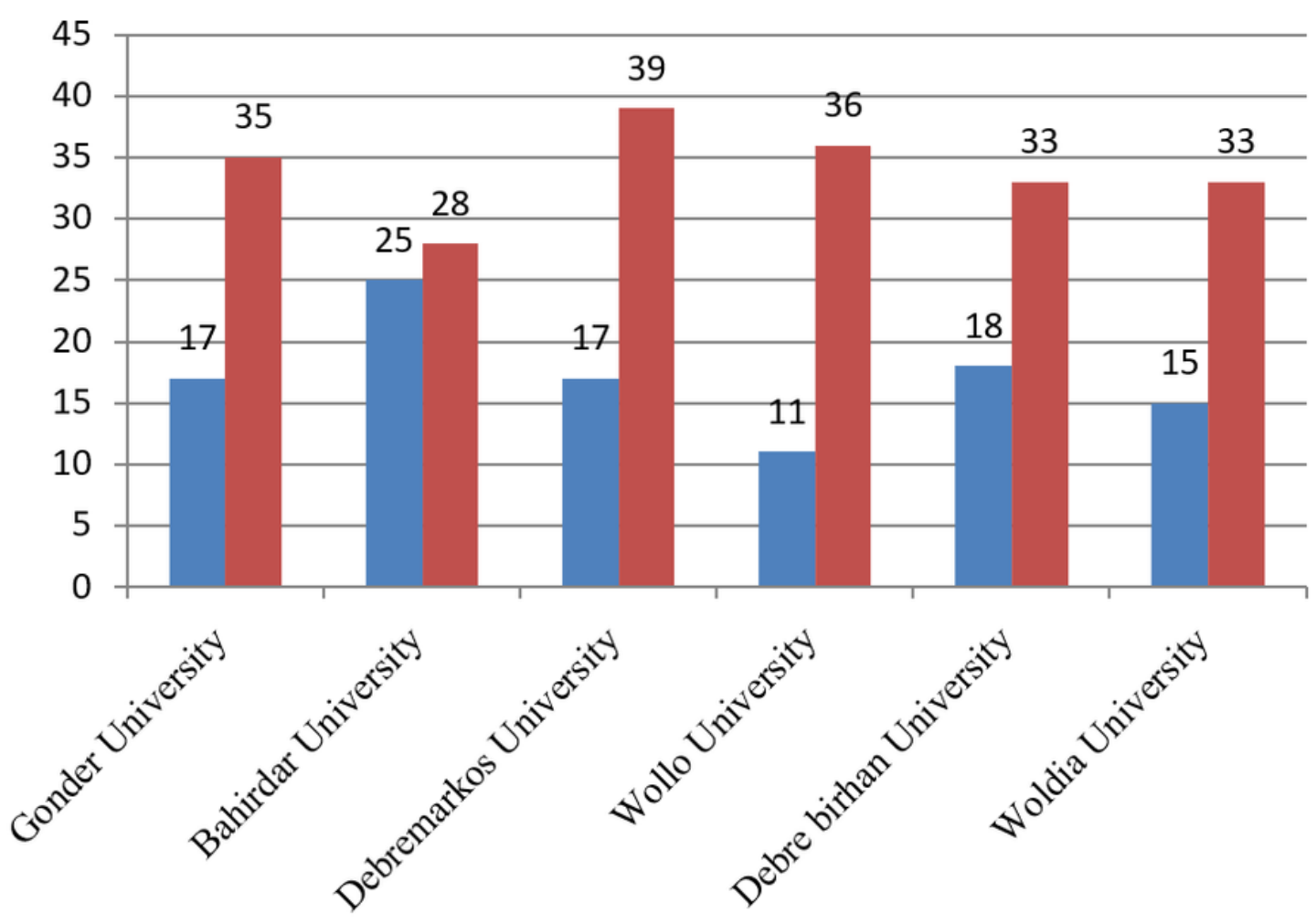

- Clinically competent

Clinically incompetent

\section{Figure 1}

Level of clinical practice competence among graduating nursing students at universities found in Amhara region, Northern Ethiopia, $2018(n=307)$.

\section{Supplementary Files}

This is a list of supplementary files associated with this preprint. Click to download.

- Table1S1.docx 